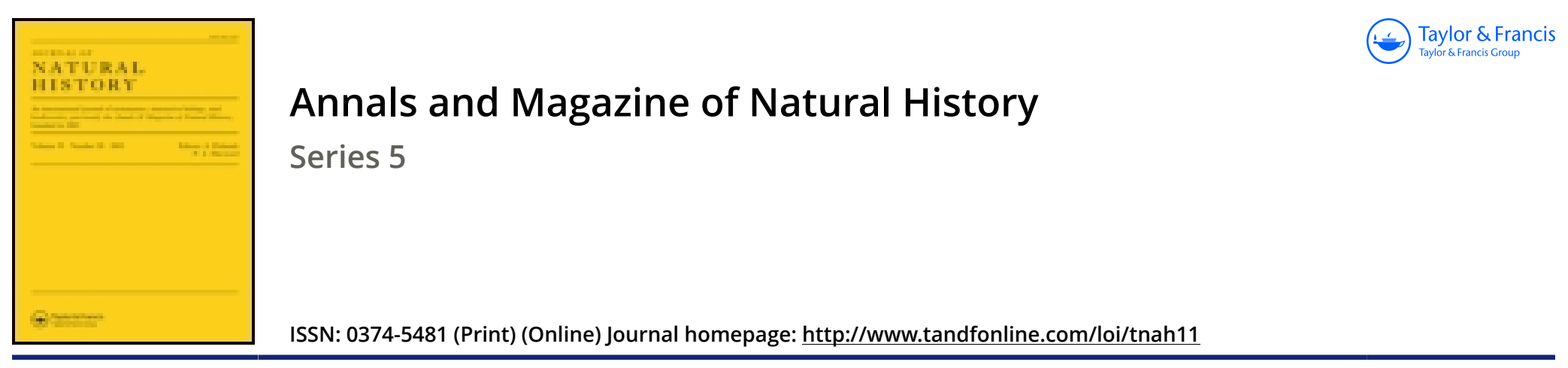

\title{
VII.-On the perfect state of Prosopistoma punctifrons
}

\section{Albert Vayssière}

To cite this article: M. Albert Vayssière (1881) VII._-On the perfect state of Prosopistoma punctifrons, Annals and Magazine of Natural History, 8:44, 73-85, DOI: 10.1080/00222938109487418

To link to this article: http://dx.doi.org/10.1080/00222938109487418

$$
\text { Published online: } 09 \text { Oct } 2009 .
$$

Submit your article to this journal $₫$

Џ Article views: 3

Q View related articles ๘ 


\section{THE ANNALS}

\section{AND \\ MAGAZINE OF NATURAL HISTORY.}

[FIFTH SERIES.]

No. 44. AUGUST 1881.

VII.-On the perfect State of Prosopistoma punctifrons. By M. Albert VAyssière*.

[Plate X.]

THE curious Arthropod that is the subject of this memoir was left, until within the last few years, in the class Crustacea, although its principal characters ought to have led to its being referred to that of Insects. It is, indeed, to this uncertainty as to its systematic position that it owes a part of the interest it has aroused.

From the extreme rarity of this animal the naturalists who had to refer to it have not always been able to verify the assertions of their predecessors. This insect was observed and figured for the first time in 1800, by Geoffroy, under the denomination of Binocle à queue en plumet, then by Latreille, who indicated it under the name of Binocle pennigère, and lastly by Duméril, who gave it the denomination of Prosopistoma, after having first of all called it Binocle pisciforme. A little later the learned Dean of the Sorbonne, M. H. Milne-Edwards, mentioned it at the end of his 'Histoire des Crustacés,'

* Translated by W. S. Dallas, F.L.S., from the 'Annales des Sciences Naturelles,' 6e sér. tome xi. (1881), pp. 1-16.

Ann. \& Mag. N. Hist. Ser. 5. Vol. viii. 
Ann \& Mag. Nat. Hist. S.5. Vol. S.PL.X.

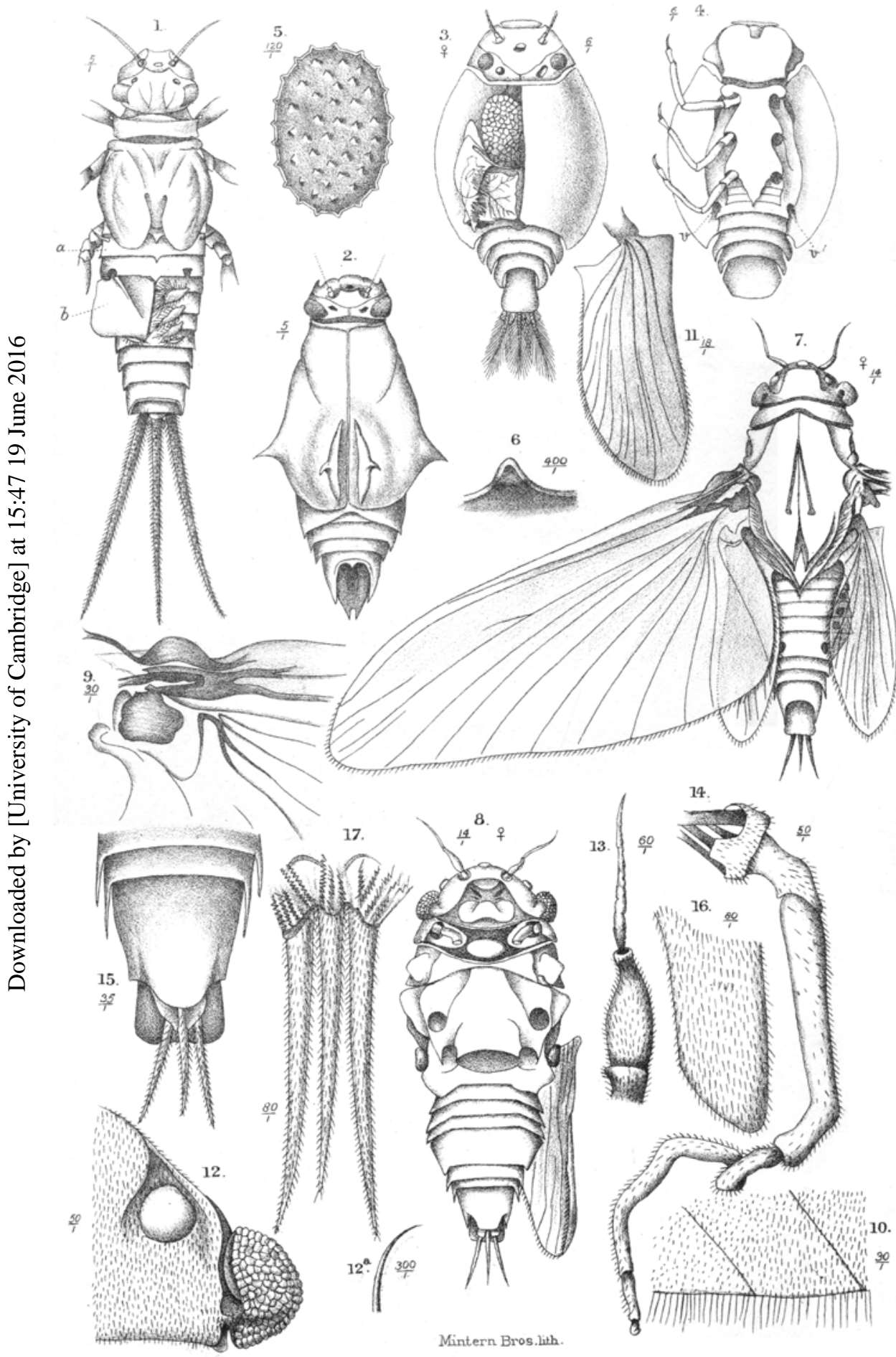


expressing some doubt as to the systematic position assigned to it by Latreille.

It was only in 1869 that my friend and collaborator, Dr. Em. Joly, having discovered its habitat in the Garonne, was able to ascertain and establish indisputably the true zoological affinities of Prosopistoma. The presence of trachex in this animal showed it to be an insect presenting numerous analogies with the larvæ of the amphibiotic Orthoptera, and especially with those of the family Ephemerina. Dr. E. Joly, in a series of memoirs published either by himself alone or in conjunction with his father, Prof. N. Joly of Toulouse, partially made known the characters of the animal, but could never succeed in witnessing its metamorphoses.

In 1878, having undertaken the whole anatomical part of a monograph on the genus, which M. Joly and myself will publish shortly, I was struck, during my first dissections, with the excessive concentration of the nervous system of this animal; and $I$ was thus led to accept the opinion expressed by Mr. MacLachlan as to the probably permanent larval condition of this insect. Having also repeatedly observed that the genital glands sometimes presented a considerable development, I set myself, from that period, to seek for its reproduction in the aquatic state; and it was in pursuing this kind of investigation upon some individuals taken in the Rhone at the beginning of April this year (1880) that I was able to observe, first of all towards the end of the same month, the change of skin of these insects (which had not previonsly been noticed), and then on the 3rd of June the metamorphosis into the perfect insect of two of them*.

In this way the question the solution of which I had vainly sought during the two preceding years, was at last solved, although in a contrary manner to what $I$ had expected.

These Arthropods therefore, in order to reproduce, followed the same course as the other Ephemerina, with which they were more intimately connected, not only by this fact, but also and especially by the more strongly marked Ephemerine facies which they present in the perfect state.

Before describing this last stage of the Prosopistoma, I think it right to say a few words as to the organization of the nymph, and to point out the analogies which exist between it and the nymphs of the genera Canis and Bcetisca.

What especially characterizes our insect in the aquatic state is the complete coalescence of the thoracic segments with the

* I immediately noticed this last fact, in a note which Prof. Blanchard was kind enough to present to the Academy of Sciences in the meeting of 7 th June, 1880. 
first segments of the abdomen, a coalescence which has superinduced a diminution of the respiratory parts and a more complete localization of those organs. In fact, instead of having, like the generality of the Ephemerina, a pair of respiratory organs or tracheo-branchice upon the sides of each of the first seven segments of the abdomen, and even presenting them upon other regions of the body (Oligoneuria, Palingenia), it possesses only five pairs of tracheo-branchia ; and, furtlier, the first two pairs, which are considerably modified, are of little service in the phenomenon of respiration, although by their movements they contribute to facilitate the physiological action of the following ones.

If, quitting Prosopistoma for a time, we examine the number and arrangement of the respiratory organs of the two types previously cited, in which an actual concentration is observed, we find:-

First of all in Canis or in Tricorythus * (fig. 1) the tracheobranchiæ, more or less modified, are reduced to six pairs. The first pair, which is completely isolated in relation to the others, consists of two fusiform bodies placed one on each side on the margins of the first segment; its physiological function must be almost null.

We then find five plates of different dimensions upon the sides of the second, third, fourth, fifth, and sixth segments of the abdoment. The first consists of two very large and very strong plates destined to protect the following ones, which they can entirely conceal; these plates, which are of a horny consistency, present the same coloration as the integuments of the body ; if they do not present digitations on their margins, each of them nevertheless possesses a small tracheo-branchial tuft at its point of insertion.

The other four pairs of respiratory organs are formed by

* It is especially by studying the nymphs of Tricorythus, for which I am indebted to the lindness of Dr. E. Joly, that I have been able to ascertain the arrangement of the respiratory organs, and to recognize the perfect similarity that exists in this stage between that genus and the genus Cemis.

+ I venture here to point out a smal] error which Mr. Eaton has left in his monograph of the Jiphemerina (Trans. Ent. Soc. London, 1871). In giving the diagnosis of the genus Cenis (p.92) he says ". . Scomentorim abdominis $1,3,4,5,6,7$ branchifera;" whereas it ought to be "Segmentorum ahdominis 1, 2, 3, 4, 5, 6 branchifera." It is to the posterior uarrin of the second segment that the respiratory plate is articulated, and not to the nargin of the third ; for the latter bears the following tracheo-branchia, and so on to the sixth segment inclusive. The seventh segment of the abdomen has never shown me respiratory organs, as, indeed, might be expected, seeing that they could not be protected by the plate covering the four preceding pairs. 
plates of much smaller dimensions, presenting numerous digitations on their margins. The respiratory functions being specially devolved upon these organs, it is a matter of course that they do not present the same consistence as the large plates; and their external envelope is even very delicate in the digitate parts.

While we have in this genus a very marked localization of the tracheo-branchial organs, such as is not observed in the commonest Ephemerina, we shall find in the next type a still greater localization, which has induced a concentration of various regions of the body. In fact in Bcetisca (fig. 2) we only find five pairs of respiratory organs, all of which fulfil the physiological function devolved upon them. These organs present the appearance of very delicate plates with more or less digitate margins. These plates are not protected, as in Ccenis, by one of their number modified for the purpose, but by a considerable development of the dorsal part of the thoracic integuments, which forms a prolongation reaching nearly to the sixth segment, thus giving origin to a sort of large carapace, under the shelter of which the respiratory apparatus performs its functions without running the risk of being damaged by contact with surrounding bodies. The movements executed in these tracheo-branchial plates give rise to a continuous current of water in this great cavity, which is directly in communication with the exterior at its posterior part and sides. 'The animal can even slightly raise this carapace, at the same time causing its abdomen to execute a movement in the opposite direction, and thus facilitate the introduction of the surrounding liquid.

There is no doubt that an equally great concentration of the various systems of the organism, and especially of the nervous system, is in correlation with this considerable localization of the respiratory apparatus, as also with the coalescence of the thoracic segments.

Let us return now to the examination of the same organs in Prosopistoma punctifrons. We observe an equally complete localization of the respiratory organs; but here the general concentration is more strongly marked (figs. 3, 4).

In the first place, the first thoracic segment or prothorax, which in the preceding Ephemerine (Batisca) was still somewhat distinct, is intimately soldered to the mesothorax without showing any traces of the union at the dorsal surface. The carapace formed by the prolongation of the dorsal integuments of the thorax cannot, in Prosopistoma, perform any movements, seeing that it is soldered to the neighbouring integuments by its lateral and posterior margins. The cavity 
which it forms, and which we shall designate the respiratory chamber, is put into communication with the exterior only by three apertures-one dorsal and median, two ventral and lateral. The water destined for respiration penetrates by the ventral apertures (fig. $4, v, v^{\prime}$ ), and, after having aerated the tracheo-branchir, issues by the dorsal opening. This current of water is produced by the movements of the tirst two pairs of respiratory organs. The two very elongated plates of the first pair are destined to cause the entrance of the liquid by the ventral apertures, while the two large quadrangular plates which form the second pair expel it by the dorsal aperture. The other three pairs of respiratory plates, which can only be detected by removing the quadrangular laminæ, present numerous digitations, which facilitate the interchange of gases *.

Of course the nervous system participates in this general concentration of the integuments of Prosopistoma. It consists :-(1) of a pair of cerebroid ganglia, closely applied to one another, and innervating the organs of the senses (eyes, ocelli, and antennæ) ; (2) of a single suboesophageal or pharyngeal ganglion, which furnishes numerous nerves to the various regions of the head; and (3) of a very voluminous thoracic ganglion, which represents of itself the whole ganglionic chain, and consequently sends forth nervous trunks to all parts of the thorax and abdomen. Upon the contour of this nervous mass we may sometimes observe swellings indicating the original existence of three pairs of thoracic ganglia and of one abdominal ganglion.

I think that the details I have just given as to the organization of Prosopistoma in the nymphal state, as well as the resemblance that can be set up between this insect and the nymphs of the two most nearly related genera, will be of service towards the ready comprehension of the importance of the modifications which I have ascertained to occur in the perfect insect, and to justify the uncertainty in which, like many other naturalists, I found myself as to the final state of this Arthropod.

It would appear that the metamorphoses of Prosopistoma into the subimago and imago must take place in the course of June; at least, as I have stated in my note to the Academy, this is the period at which $I$ ascertained the fact, and a period nearly the same as that at which many Ephemerina are metamorphosed.

* It is very probable that the insect at its escape from the egg does not possess tracheo-branchix, and that respiration is effected for a certain time through the skin of the general surface of the body; the carapace must be more or less incomplete during this larvular phase. 
The following are the modifications observed in the nymph when it is on the point of being transformed. During the whole of the aguatic period known to us the integuments of Prosopistoma present a very light chitine-yellow tint, nearly white if the insect has just moulted, and more or less marked at other times; but at the commencement of the transformation the colour becomes darker from day to day, and soon becomes very brown. It is especially in the posterior part of the carapace above the respiratory chamber that this coloration becomes very strongly marked, which is easily explained, as it is at this point that the wings are formed, and these, as we shall see hereafter, are iron-grey in the subimago.

At the end of about a fortnight, when the general colour becomes blackisl, it is possible, under a low power, to observe by transmitted light the outlines of the perfect insect through the nymphal envelope; and it is then necessary to watch the animal, as the metamorphosis will soon take place. In two or three days one may see the animal cling to a stone partly out of the water, and divest itself of its nymphal integuments; and it is to be remarked that the metamorphosis takes place very early in the morning.

The two parts of the carapace begin to separate in the median line of the body, under the pressure from below upwards exerted by the animal; then the anterior margins of the same region and the posterior part of the cephalic integuments (the epicranium) also separate. The insect can then free its head and the whole of its thoracic part; the buccal organs and the legs escape easily from the nymphal envelope, owing to the state of atrophy in which they always are in the perfect animal. The Prosopistoma afterwards frees its abdomen; and at the same moment we see issue from it the wings, which, originally folded longitudinally in three parts, immediately acquire their definitive form. The insect can then take to flight, to go and rest on some point at a distance from the water ; and there it divests itself of its subimago envelope.

I have been unable to observe this last metamorphosis of the adult Prosopistoma, the two female subimagos that I had having died soon after stripping off their nymphal envelope; it is quite possible that the females of this genus oviposit in the state of subimago, and do not attain that of imago. According to Mr. Eaton the fernales of various types of Ephemerina only present a single stage in the perfect state*.

* At the end of p. 42 of the Monograph of Ephemerina of the English naturalist (loc. cit.) we find the following phrase:--" In certain genera the subimago is the permanent aerial stage of the females." 
The facies of Prosopistoma punctifrons in this state (fig. 7) resembles that of Canis; its body is a little shorter in proportion to its breadth, which gives the animal, when its wings are extended, a certain vague resemblance to some Diptera.

The general colour of the integuments of the subimago is reddish brown, darker on the dorsal than on the ventral surface, where the tint even becomes very light at certain points (at the insertions of the legs); the wings are of a pretty dark iron-grey, especially the first pair.

The coalescence of the different regions of the body no longer exists in so marked a manner in the perfect state; on the contrary they are very distinct. I now proceed to give a detailed description of each of them, and to show the importance of the modifications superinduced by the metamorphosis.

The head is slightly triangular in form. When seen from above, it shows in the middle an inflated part bounded in front and on the sides by a sinuous line. In front of this line is the median ocellus, which forms a slight projection beyond it; on each side of this we observe the antenne, the points of insertion of which are rather on the ventral than on the dorsal surface; behind we see the lateral ocelli placed on each side of the cephalic prominence, at the points where the sinuous line already mentioned becomes confounded with the integuments. The compound eyes occupy quite the lateral parts of the base of the head (figs. 7,8 ) ; in consequence of their position, they are equally visible whether the animal is viewed from the upper or the lower surface.

The ventral or inferior surface of this first region of the body (fig. 8) shows in front the points of insertion of the antennax; the median ocellus, which, as just stated, is placed between these organs, is more or less distinct according to the inclination given to the body of the animal; further back there is a strongly marked line bounding the clypeus, which, in consequence of a special modification, terminates rather low down on the ventral surface. It is in the interior of the concavity formed by the margins of the clypeus that all the buccal organs are placed. The large labium, which led to the name of Prosopistoma being given to the nymphal state, from its resemblance in this species to a mask (see fig. 4), has become completely atrophied, and leaves exposed the rudiments of the maxillce and mandibles; of all the buccal organs the labrum is the only one that has retained a well-detined form.

In the dorsal view of the animal (fig. 7) the thoracic region presents an exceedingly short prothorax, the anterior margin of which is slightly convex in the middle, while the posterior margin is a little concave. 'Then follow the mesothorax and the 
metathorax, which are closely soldered together and present in their middle an inflated portion, a sort of lozenge-shaped plate; this plate is divided, in the direction of the length of the body, into two equal and symmetrical parts, each of which presents on its inner margin a rather deep notch (which, however, does not go very far), and then posteriorly an emargination. On the lateral parts of this plate there are a series of nodosities and folds, symmetrically arranged on the two sides of the body, and serving as points of insertion for the wings; I think it would be tiresome to enter here into the description of these nodosities, and I shall only say a word or two about them further on in speaking of the wings.

The ventral surface of the thoracic region (fig. 8) shows in front the prothorax distinctly separated from the rest; upon the somewhat lateral parts are the points of insertion of the first pair of legs. 'These are separated from each other only by a rather wide prominence of a strong reddish-brown colour.

A portion of the mesothorax is distinct on this surface, although its lower two thirds are intimately united with the metathorax. The insertions of the legs of the second and third pairs upon the thorax are placed almost upon the sides of a large strongly chitinized plastron, which of itself constitutes the lower surface of this region of the body.

The abdomen remains to be mentioned. On the dorsal surface (fig. 7) this presents ten well-marked segments, except the first, of which the anterior margin is confounded with the metathorax; but on the ventral surface (fig. 8) it only exhibits eight, the boundaries of the first two having completely disappeared, and their union with the thoracic region being as intimate as possible.

The segments of the abdomen are not all of the same form and the same dimensions. Thus, when seen from the dorsal surface, the second, third, fourth, and fifth segments represent in form each a very wide trapezium; the sixth shows the same form, but reversed, the large base or lower base of the trapezium being in front, while the superior base is behind; it is also much longer than the precediug, but not so wide. The seventh and eightl segments are nearly rectangular, while the ninth presents the appearance of a reversed trapezium, of which the small base is much emarginate; finally, the last abdominal segment, that which bears the setæ, nearly forms a square.

These various segments, which are more convex on their dorsal than on their ventral surface, are not, however, all equally so; thus the sixth segment is a little more inflated than the preceding ones, and the nintl much more so. 
The first five segments of the perfect insect represent those which, more or less soldered together, occupy in the ventral surface of the nymph all the space included between the last pair of feet and the lower part of the ventral apertures (fig. 4) ; the sixth is formed by that to the dorsal surface of which the extremity of the carapace is soldered; the seventh and eighth correspond to the first two free segments of the abdominal region of the nymph; the ninth has nearly the same form in these two states of Prosopistoma; for in both cases it performs nearly the same part, nainely the protection of the last segment. The latter in the subimago is composed of a dorsal plate, which is homologous with the dorsal surface of the same segment in the aquatic insect, and of two atrophied plates which, placed over the setæ, represent the two plates of the ventral surface of this tenth segment in the larval and nymphal forms of the Prosopistoma. The mobility of these inferior plates is far from being so great in the perfect insect, seeing that the setæ have lost the faculty of withdrawing themselves completely into the interior of the penultimate segment. We have observed only four pairs of stigmata, placed on the sides of the dorsal surface of the third, fourth, fifth, and sixth segments ; we believe, although we have not been able to ascertain it de visu, that there are also stigmata upon the second segment.

It remains for us to add to what has just been said on the form of the various regions of the body that all the integuments are covered with simple hairs, more or less closely adpressed to each other according to the parts examined; these hairs are also abundant upon the surface of the appendicular organs.

We now proceed to examine the organs of the senses, the legs, the wings, and the setæ, which we have hitherto passed over.

Antenna.-In the nymph the organs of touch are formed of six joints, which are unequal but have nearly the same form; this is no longer the case in the perfect state (fig. 13), in which the antennæ have only two very unequal joints and a flagellum. The basal joint, of a cylindrical form, is rather short; the second, on the contrary, is at least three times as long, inflated in the middle, and attenuated at the apex; both these joints are of a brown colour, and are also covered with a great abundance of hairs.

The flagellum, which is inserted at the extremity of the second joint, is of itself as long as the rest of the antenna; it is very slender; and its tegumentary envelope, which is destitute of hairs, presents a very pale brown colour. 
Compound Eyes and Ocelli (fig. 12). -The compound eyes show a strongly marked black tint; they are inserted upon the outer, lateral margins of the head, nearly at the intersection of these margins with its base. They are hemispherical. On the dorsal surface of each of them, a little behind the middle, we observe a groove, which does not surround it completely. This peculiarity places these organs of vision in the section of ascalaphoid compound eyes of certain Ephemerina (Leptophlebia). The facets of these organs are not always hexagonal ; they often present only four or five sides; or their outlines may even be irregular.

The ocelli, with their very convex cornea, are easy to distinguish even by the naked eye, owing to their whitish colour. The lateral ocelli are placed within and a little in front of the compound eyes; the median ocellus, as already stated, occupies the middle of the space between the antenna, and is almost in the anterior margin of the head.

Legs.-The organs of locomotion are all atrophied in the perfect insect; this modification, which is observed in a great many other adult Ephemerina, must be in relation to the short duration of the life of the animal in this state; it is therefore very probable that, after copulation (and oviposition in the case of a female), Prosopistoma punctifrons speedily dies. We hope that future investigations will soon enable us to fill up this gap.

The legs are very unequal: the shortest are those of the first pair, and the longest belong to the third pair (fig. 14). The colour of these organs is very light brown, depending somewhat upon the thinness of the chitinous envelope, the surface of which also is but little clothed with hairs. The first two joints, coxa and trochanter, are pretty well formed in all the legs, and are even strongly developed in those of the first pair; the form of the femur of the anterior limbs is not much modified, whilst it is more or less modified and atrophied in the other legs. The last three portions, tibia, tarsus, and claw, are always deformed, and often actually twisted into a corkscrew, in all the legs.

In the figure of the insect seen from the ventral surface I lave represented (fig. 8) only the first two joints of the first pair; in fig. 14 I have given a representation of one of the legs of the third pair under a power of about 50 diameters. In this last pair the general atrophy is more marked even than in the two others.

Wings.-The organs of flight are greatly developed in Prosopistoma, which is not surprising, considering the atrophy of the legs, and the necessity under which the insect in con- 
sequence finds itself, of flying throughout the whole of its perfect state.

It has already been stated that the wings are formed above the respiratory organs, in sheaths which only become developed a little while before the metamorphosis of the animal. The sheaths destined to produce the upper wings originate in the interior of the integuments which cover the tracheo-branchiæ- that is to say, under the posterior part of the chitinous envelope of the carapace; the hinder wings are formed in the interior of those two plates which, in the aquatic state of Prosopistoma, appear to be formed to protect the points of insertion of the first two pairs of tracheobranchia (fig. $3, f$ ). These plates must be formed very early in our animal; for I have always observed them in the same state of development in more than fifty individuals of all sizes. The upper wings, or wings of the anterior pair, affect the form of right-angled triangles, of which the hypotenuses are represented by the anterior margin; their inner margin, as in all Ephemerina, forms the shortest side (see fig. 7).

The longitudinal nervures of these superior wings are not numerous; and transverse nervures are entirely wanting. The base of the two strongest nervures (anterior nervures) constitutes, with a thickening of the margin of the wing, the principal part of the articulation with the two strongest projections observed on the sides of the thorax. Bclow the two anterior nervures we find three others which do not reach the articulation of the wing ; the five following nervures, which succeed one another at nearly equal distances apart, as they approach the inner margin of the wing, terminate at the base of the wing, with the exception of the last, which is shorter and more delicate than the others. The anal nervure starts from a chitinous thickening of the basal region of the organ of flight, and terminates on the inner nargin, nearly at the point where this becomes rounded to form the posterior margin.

The wings of the second pair, of an oval form, are much smaller and more delicate (fig. 11) ; their principal point of insertion is upon the nodosity which may be noticed on each side of the metathorax at the level of the points of attachment of the last pair of legs. When the fore wings are extended, the apical extremities of the others slightly exced the abdomen on each side; when the animal is in repose the ordinary position of the wings is the same that is observed in all the Ephemerina: they are placed vertically above the body, and a little inclined towards each other. The inner and posterior margins of these different wings presented long delicate hairs (fig. 10); but the surface itself of the wings was covered with 
very short and abundant hairs; the latter character occurs in all the subimagos of Ephemerina.

Seto.-C.The setæ (fig. 17) are far from showing the same complication of structure in the perfect insect as in the nymph. They are borne by the last segment, in the cavity of which they can no longer shelter themselves, the apparatus destined to make them enter into the interior of the body having become atrophied, because, in the perfect state, it would be of no use to the insect to retract them; the last joint can still, however, in part withdraw itself into the ninth. We no longer observe traces of annulation on the surface of the setro; and the hairs which clothe them are very short and very irregularly arranged.

I have carefully dissected the only two examples of the subimago that $I$ have been able to procure. Both of them being females, I found in the interior of their visceral cavity a great quantity of eggs (about sixty in each). These eggs (fig. 5) were about ${ }^{1}$ millim. in length; their form was distinctly ellipsoidal; their surface presented a multitude of pretty strong rugosities, into which the vitelline mass penetrated (fig. 6) ; and their colour was milk-white. These eggs, from their general external characters, and especially the absence of the hood or cap at their two extremities, greatly resemble those of Cloë diptera. After having freed the visceral cavity of all the eggs, I observed the empty state of the digestive tube and the atrophy of all the glandular organs of that apparatus, which had either completely disappeared, like the yellow hepatic layer of the stomach, or partially, like the Malpighian tubes.

The nervous system presented the same degree of concentration as in the nymph. It consisted of a pair of cerebroid ganglia, a cordiform subœsophageal ganglion, and a single large thoracic ganglion representing the whole of the ventral chain.

The tracheal apparatus consisted of two lateral trunks, sending forth numerous ramifications to all parts of the body, and connected with the four or five pairs of stigmatic apertures by means of very short secondary trunks.

As the perfect state of Prosopistoma punctifrons is now known, my collaborator, Dr. E. Joly, and myself intend changing the name of the animal, in order to conform to the entomological usage according to which the denomination of an insect should not be derived from a larval character, as is the case with Prosopistoma; and it is in the monograph of the genus, which we shall not delay to publish, that the definitive diagnosis of this Ephemerine under its new denomination will be found. 


\section{EXPLANATION OF PLATE $X$.}

The numbers placed beside the figures express the enlargement in diameters.

Fig. 1. A nymph of Tricoryphus (sp. ?), $\times 5, a$, rudimentary respiratory organ of the first segment; the chitinous plate, $b$, has been removed on one side to show the following respiratory organs.

Fig. 2. Batisca obesa, seen from above and drawn from a nymphal envelope, in which the last segment and the antennæ were deficient, $\times 5$.

Fig. 3. Prosopistoma punctifrons, nymphal stage, seen from above, $\times 12$. The left half of the carapace has been removed to show, in front, the digestive tube partly concealed by the left lobe of the genital gland; behind, the interior of the respiratory chamber, in which is the sheath of the lower wing $(f)$ concealing the points of insertion of the first two tracheo-branchio.

Fig. 4. Prosopistoma punetifrons, nymphal stage, seen from below, $\times 12$. The last segment, with the setre, has withdrawn into the ninth segment; at $v$ and $v^{\prime}$ are the apertures which give the water access to the respiratory chamber.

Fig. 5. One of the ova found in the body of the subimago of Prosopistoma, $\times 120$.

Fig. 6. One of the nodosities of this ovum, much enlarged, $\times 400$.

Fig. 7. Female (subimago) of Prosopistoma punctifrons, seen from above, $\times 14$. The stigmatic apertures may be seen on the right side of the third, fourth, fifth, and sixth segments.

Fig. 8. The same, seen from below, $\times 14$. In order to avoid making this figure too complicated, I have not represented the legs of the second and third pairs, and I have left only the first two joints of those of the first pair.

Fig. 9. Base of the jnner surface of an upper wing, $\times 30$.

Fig. 10. Fragment of the posterior margin of the same wing, to show the multitude of hairs which cover both surfaces of the organs of flight, $\times 30$.

Fig. 11. Lower wing, $\times 18$.

Fig. 12. Right compound eye and lateral ocellus, in their respective position, $\times 30.12 a$ is a hair from the integument of this region, much enlarged.

Fig. 13. Anternæ, $\times 60$.

Fig. 14. Leg of the third pair, $\times 50$.

Fig. 15. Ventral surface of the abdomen of the female subimago, $\times 85$.

Fig. 16. One of the two plates forming the ventral surface of the last segment, $\times 80$.

Fig. 17. The three setæ of Prosopistoma in the perfect state, $\times 80$.

N.B. In several of the figures I have not represented the villosity due to the presence of the hairs which cover the integuments and the wings of the subimago.

VIII.-Notes on Indian Land and Freshwater Mollusks.No. I. On the Discrimination of the Sexes in the Genus Paludina. By J. Wood-Mason, Deputy Superintendent, Indian Museum, Calcutta, on Special Duty in Assam.

WHile at Balaganj and Panchuganj, on the Kusiara river, in Central Sylhet, on my way to Cachar, I was struck by the 